\title{
La polémica de las ilicitudes probatorias derivadas de las fases de la cadena de custodia y el rango de la norma quebrantada
}

\section{Resumen}

Emma Calderón Arias*

El tema de las ilicitudes probatorias se muestra en la doctrina y en la praxis jurídico penal, como uno de los más importantes y esenciales relativos a probar los hechos con caracteres de delito. Es la cadena de custodia una de las instituciones que contribuye a la integridad y autenticidad del material probatorio, para que llegue al acto del juicio oral tal cual fueron obtenidos en el lugar de los hechos, garante a la vez de un debido proceso. Pero cuando transcurren las diferentes etapas de la cadena de custodia, puede que se rompa algún eslabón de la misma y por consiguiente se vulneren derechos fundamentales o garantías procesales, aspectos de interés para las denominadas ilicitudes probatorias.

Palabras clave: Delito, cadena de custodia, prueba, prueba ilícita

\section{The range of the norm smashed as polemic point in the derived probatory illicitness of the phases of the custody chain}

\begin{abstract}
Abstrac
The topic of the probatory illicitness is shown in the doctrine and in the penal juridical practice, like one of the most important and relative essentials to prove the facts with crime characters. It is the custody chain one of the institutions that contributes to the integrity and authenticity of the probatory material, so that it arrives to the act of the such oral trial which you/they were obtained in the place of the facts, at the same time guarantor of a due process. But when the different stages of the custody chain lapse, he/she can that it breaks some link of the same one and consequently fundamental rights or procedural guarantees are harmed, aspects of interest for the denominated probatory illicitness.
\end{abstract}

Key words: Crime, custody chain, proves, it proves illicit

*Universidad de la Habana, Cuba.emma830913@gmail.com 


\section{Sumario:}

1. Introducción. 2. Fundamentos teóricos de las ilicitudes probatorias. 3. Criterios de clasificación sobre ilicitudes probatorias. 4. El rango de la norma quebrantada como centro de la polémica. 5. Consideraciones finales. Bibliografía.

\section{Introducción}

Fue la confesión "reina de las pruebas" en uno de los sistemas de enjuiciar, y el actuar en el proceso de enjuiciamiento se encontraba desprovisto de garantías. En esos momentos se obtenían los elementos de prueba de forma contraria a los derechos y libertades de las personas, aspecto que resulta de mucho interés para nuestra investigación, ya que en la doctrina, cuando de cadena de custodia se habla y de sus eslabones o etapas, al violarse alguna de ellas traerá consigo determinadas consecuencias, y uno de los puntos en los que deriva es la ilicitud de la prueba, con la consiguiente nulidad o anulabilidad del acto. En este espacio estaremos ubicados en la trascendencia del significado de las ilicitudes probatorias para la cadena de custodia.

Con la valoración de las garantías y un proceso penal acorde a los límites establecidos por los derechos fundamentales, resultado del movimiento iluminista con las ideas de igualdad y humanismo, es que se fue poco a poco democratizando el proceso penal, el cual empezó a convertirse en una verdadera contienda entre partes, más cercano al ideal del debido proceso, con mecanismos de amparo para el acusado y demás sujetos del proceso, de conjunto con la conformación del sistema mixto como se ha explicado.

Ahora bien, de todos los eslabones o etapas de la cadena de custodia puede que alguno falle, o se viole, y se contaminen dichos elementos de prueba, o se vulneren derechos fundamentales, garantías establecidas en ley, y es por ese camino que se centra la polémica sobre la prueba ilícita, pues no está sólo en la definición de la misma, sino también por el rango de la norma quebrantada. 


\section{Fundamentos teóricos de las ilicitudes probatorias}

Aún no existe consenso doctrinal sobre la definición de prueba ilícita, al respecto se presentan criterios de varios autores que trataremos a continuación, para De Diego Dízz ${ }^{1}$ la actividad probatoria solo puede realizarse a través de la introducción de medios lícitos de prueba. Lo que quiere ponerse de manifiesto es que la obtención de las fuentes de prueba y su introducción en el proceso han de hacerse con escrupuloso respeto hacia los derechos individuales reconocidos en la Constitución, (tales como derecho a la libertad personal, integridad física psíquica y moral, la intimidad personal y familiar, el de defensa, la no autoincriminación, inviolabilidad del domicilio...). Todos ellos sirven como referente y elemento exegético básico para determinar si algún elemento de prueba ha sido obtenido vulnerando alguno de los derechos individuales $\mathrm{y}$, como tal, da lugar a la prohibición de valorar su resultado probatorio.

Es prueba ilícita para FERRER BeLtRÁN ${ }^{2}$ la que se obtiene con vulneración de garantías constitucionales - la inviolabilidad del domicilio, el secreto de las comunicaciones, la transcripción de unas escuchas telefónicas sin cumplir los requisitos legales establecidos - o lesionando derechos constitucionales - el derecho a la defensa -, o a través de medios constitucionalmente prohibidos - la tortura, que vulnera el derecho a la integridad física, o una coacción para obtener declaraciones.

'De Diego Díez, Luis Alfredo. Cuadernos de estudios judiciales "Rafael Alvarado Manzano". Los medios de prueba. Tegucigalpa, Honduras. 2001, p.7.

${ }^{2}$ Ferrer Beltrán, Jordi, Gascon Abellan, Marina, González Lagier, Daniel, Taruffo Michelle. (2006): "Estudios sobre la prueba”. Universidad Nacional Autónoma de México. Instituto de Investigaciones Jurídicas México, p. 56 y 57. "Es prueba ilícita la que se obtiene con vulneración de garantías constitucionales (como la inviolabilidad del domicilio o el secreto de las comunicaciones: por ejemplo, el acta de entrada y registro practicada sin consentimiento del titular o resolución judicial, o la transcripción de unas escuchas telefónicas practicadas de la misma manera); o lesionando derechos constitucionales (como el derecho a la defensa: así, la declaración del imputado sin haber sido informado de sus derechos); o a través de medios que la Constitución prohíbe (por ejemplo, la confesión arrancada mediante tortura, que vulnera el derecho a la integridad física, o una coacción para obtener declaraciones sobre "ideología, religión o creencias", proscrita por el derecho a la libertad ideológica y de conciencia). En definitiva, y por simplificar, es ilícita la prueba obtenida en violación de derechos fundamentales." 
Afirma además dicho autor ${ }^{3}$ que la prohibición de prueba ilícita no requiere regulación legislativa expresa, sino que deriva directamente de la Constitución por la posición preferente de los derechos fundamentales en el ordenamiento y su condición de inviolables. Dicho de otro modo, la regla de exclusión de la prueba ilícita deriva de la Constitución porque el objeto de ésta es la protección del pueblo contra actuaciones arbitrarias como las que tienen lugar cuando la policía viola derechos. Pero existen al menos dos modos de articular este fundamento constitucional de la regla que pueden acarrear consecuencias distintas para su fortaleza.

A. El derecho a un proceso con todas las garantías. Puede sostenerse, por un lado, que la regla de exclusión de la prueba ilícita está directamente alojada en el derecho constitucional al proceso debido (due process of law). Lo que se sostiene, con más precisión, es que dicha regla es la expresión de una garantía implícita en el sistema de los derechos fundamentales, pues la posición preferente que ocupan en el ordenamiento exige rechazar toda prueba obtenida con lesión de los mismos, y que esa garantía se plasma en el derecho al debido proceso.

B. La tesis del efecto preventivo o disuasorio de la exclusión. Pero puede sostenerse también que la regla de exclusión de la prueba ilícita no tiene su fundamento constitucional en un concreto derecho, ni viene implícita y directamente exigida por la Constitución como la única salvaguarda efectiva de los derechos constitucionales, sino que su fundamento reside en la necesidad de producir un efecto preventivo o disuasorio sobre las conductas que lesionan derechos. Esto es lo que sucede en Estados Unidos. En la jurisprudencia norteamericana, en efecto, la justificación canónica de esta exclusionary rule, desde mediados de la década de los setenta del pasado siglo y hasta la fecha, no reside en un supuesto derecho constitucional subjetivo de la parte agraviada, sino en la necesidad de disuadir de la violación de los derechos (deterrent effect); y por ser más precisos, en la necesidad de

${ }^{3}$ Ídem, p. 53 
disuadir de futuras lesiones de derechos constitucionales por parte de los poderes públicos y singularmente de la policía.

C. La tesis española de la conexión de anti juridicidad. La conexión de anti juridicidad es una construcción teórica del Tribunal Constitucional español mediante la cual se pretende explicar cuándo deben ser excluidas del proceso y cuándo no las pruebas obtenidas a raíz de la lesión de un derecho fundamental. Esta tesis parte del presupuesto de que no toda prueba obtenida a partir de la lesión de un derecho ha de ser considerada ilícita y por tanto excluida. Lo será sólo en determinadas circunstancias, y de estas circunstancias da cuenta justamente la doctrina de la "conexión de anti juridicidad".

Cuando se ha lesionado un derecho fundamental y como consecuencia se han obtenido pruebas, éstas no son inadmisibles en todo caso, sino sólo cuando exista, además de la relación de causalidad, una conexión de anti juridicidad entre la lesión y las pruebas.

Esta postura valorada anteriormente por FERRER BELTRÁn responde al debate que se ha ido presentando alrededor de la prueba ilícita en torno a la regulación o no de la misma en norma, pues para él, deriva directamente de la Constitución por la posición que tiene respecto a los derechos fundamentales; sin embargo por otro lado se encuentra RAmos RUBIO ${ }^{4}$ para quien la prueba ilícita se refiere exclusivamente a la que es obtenida violentando derechos y libertades fundamentales, de manera que por definición se concibe otra suerte de ilicitud probatoria simplemente ordinaria, que se ha dado en llamar prueba irregular, cuyos efectos no podrían ser parejos a la anterior, por mor del derecho fundamental a la prueba.

Las diferencias entre la prueba ilícita y la irregular para RAmOs RUBIO ${ }^{5}$, en orden a la eficacia probatoria en el proceso penal no son sin embargo apreciables en un primer grado, ya que tanto una como otra carecen de virtualidad al respecto, dependiendo en el segundo caso de la naturaleza, gravedad y acumulación de

${ }^{4}$ Ramos Rubio, Carlos, Manuales de formación continuada número 12. "La prueba en el proceso penal", p. 19. Consejo General del Poder Judicial, Madrid, 2000. 5́́dem, p. 23 
irregularidades, y, sobre todo, de la indefensión provocada. En un segundo grado, en relación con las pruebas relacionadas con ellas, ya que para las derivadas de las pruebas ilícitas se impone a sí mismo la ineficacia como lógica consecuencia de una suerte de contaminación, mientras que para las derivadas de las siguientes irregulares no se produce tal radical consecuencia. Esta diferencia se resuelve en la práctica, por tanto, en la posibilidad de recuperación del material probatorio evidenciado por la prueba irregular, mediante su conversión en algún otro tipo de prueba subsidiaria, generalmente la testifical o la confesión, como modo de subsanación, posibilidad que es impensable en el caso de la prueba ilícita.

Una perspectiva interesante resulta la de Armenta Deu ${ }^{6}$ que destaca dos aristas sobre el tema de la prueba ilícita, una es la angloamericana ${ }^{7}$ que se centra en regular los medios de prueba y su obtención, sin que exista a priori reglas de exclusión, en tanto los sistemas continentales centran sus esfuerzos en los medios de adquisición de las fuentes de prueba, aspecto regulado específicamente bajo pena de nulidad ${ }^{8}$.

Explica Tínoco Pastrana9 que la exclusionary rule es una regla que ha sido creada por la Corte Suprema de los Estados Unidos a partir de la IV Enmienda, que comporta la inadmisión de las pruebas ilícitas, u obtenidas con la violación de los derechos fundamentales. De acuerdo con la fruit of poisonous tree doctrine (doctrina de los frutos del árbol envenenado), esta

${ }^{6}$ ARMENTA DeU, Teresa: La prueba ilícita (un estudio comparado) Segunda edición. Ediciones
Jurídicas y Sociales, S.A. Marcial Pons. Madrid. Barcelona. Buenos Aires. 2011, p. 21
'Ídem, p. 22, refiere la autora como en el adversaryal sistem estadounidense la doctrina sobre
la exclusionary rule se centra en contener los posibles abusos que puedan producirse en los
derechos por parte de los responsables públicos en la persecución de los hechos delictivos.
${ }^{8}$ Ibídem, Mientrasqueparalospaísescontinentaleselrespetosecentraenelprincipiodelegalidad,
que exige que la obtención de laverdad siga los parámetros de unprocesolegalmente establecido.
A partir de ahí, las configuraciones inciden especialmente en el difícil equilibrio a que se somete
la conjugación de intereses tan contrapuestos como legítimamente dignos de tutela; así a título
de ejemplo y acudiendo a una formulación general: la protección y castigo de las conductas
infractoras y la tutela de intereses individuales, excluyendo concretos medios de prueba.
${ }^{9}$ Tinoco PASTRANA, Ángel: Fundamentos del sistema judicial penal en el Common Law.
Secretariado de Publicaciones, Universidad de Sevilla. 2001 , p. 127 
regla no se restringe a la prueba directa, sino que también se aplica a la indirecta, es decir, a pruebas provenientes de las ilícitamente obtenidas.

También en la doctrina argentina CAFFERAtA Nores ${ }^{10}$, distingue entre la obtención ilegal o irregular de la prueba y su incorporación al proceso (según el momento en que se produce). De suerte que, la ilicitud puede producirse en dos momentos distintos: en oportunidad de recolectar la fuente de prueba y en ocasión de la introducción de dichas fuentes de prueba al proceso. Esta diferenciación es de interés desde que, son los supuestos de ilicitud extraprocesal los que con mayor frecuencia se producen en la práctica. En efecto, la mayoría de los casos analizados hacen referencia al momento de búsqueda, obtención y recogida de las fuentes de prueba situándose, por tanto, en el marco de la fase de investigación policial o judicial.

En este sentido Miranda Estrampes ${ }^{11}$ sistematiza una propuesta atendiendo al momento concreto en que se produce la ilicitud, dentro o fuera del proceso, se distingue entre ilicitud extraprocesal e ilicitud intraprocesal. La primera, es aquella producida fuera de la esfera o marco del proceso propiamente dicho, en oportunidad de la obtención de la fuente de prueba, afecta por tanto, la labor de investigación de los hechos, es decir, a la búsqueda, recogida y obtención de las fuentes de prueba (ejemplo los documentos que han sido sustraídos u obtenidos delictivamente y después incorporados a la causa). Y la intraprocesal es aquella que afecta a un acto procesal, es decir, cuando afecta la proposición, admisión y práctica de la prueba durante el proceso (ejemplo el empleo de medios coactivos en los interrogatorios del inculpado).

En los criterios de clasificación de Cafferata Nores y Miranda Estrampes donde se analiza el momento en el que se produce la ilicitud, y en el espacio referido a cuando acontece el actuar ilícito en un momento extraprocesal, no concordamos del todo, en tanto aseveran que afectará la fase de investigación

\footnotetext{
${ }^{10}$ Cafferata Nores, José I.: La prueba en el proceso penal. 1era edición, Ediciones Depalma, Buenos Aires 1986, p. 14

${ }^{11}$ Miranda Estrampes, Manuel: El concepto de prueba ilícita y su tratamiento en el proceso penal. J.M Bosch Editor, Barcelona, España, 1996, p. 26
} 
de los hechos, la búsqueda, recogida y obtención de las fuentes de prueba, $y$ es que esa fase es la llamada fase preparatoria del juicio oral, contentiva como la primera etapa o fase del proceso penal, por lo que no creemos sea extraprocesal sino antes del juicio oral. Y en este particular la licitud de los actos es importante durante todo el proceso, pero requiere especial relevancia para la cadena de custodia justo en las etapas de búsqueda, identificación, recolección, y obtención de los elementos de prueba, ya que una vez que exista alguna vulneración podríamos estar hablando de prueba ilícitamente obtenida, con las correspondientes consecuencias en el análisis pericial donde se arriban a los resultados.

Sebastián Midón ${ }^{12}$ refiere otra clasificación teniendo en cuenta la causa de la ilicitud y expone que quienes participan de la amplia concepción de la prueba ilícita, esto es, de un criterio que no se ciñe a los supuestos de obtención y práctica de pruebas con vulneración de derechos o garantías constitucionales, atendiendo la causa que origina la ilicitud, han de distinguir entre pruebas expresamente prohibidas por la ley, pruebas irregulares o ilegales, y pruebas inconstitucionales. El concepto de prueba expresamente vedada por ley queda reservado para aquellos supuestos en que exista una norma legal precisa y concreta de carácter prohibitivo. Prueba irregular, defectuosa o ilegal es aquella en cuya obtención se ha infringido la legalidad procesal ordinaria, es el supuesto en donde se ha practicado la prueba sin las formalidades legalmente establecidas para su adquisición, esto es, sin ajustarse a las previsiones o al procedimiento fijado por la ley. Y finalmente, pruebas inconstitucionales son aquellas obtenidas o practicadas con infracción de los derechos fundamentales de las personas y que dimanan expresa o implícitamente de los textos constitucionales.

Para luego, realizar una valoración que resulta interesante pues para SEBASTIÁN Midós ${ }^{13}$ la regla de exclusión en términos más menos generales, es posible afirmar que toda vez que una prueba que sirva para verificar la comisión de un delito, sea obtenida violando, transgrediendo o superando los límites

${ }^{12}$ Sebastián Midón, Marcelo, op. cit. p. 41 y 42

${ }^{13}$ Ídem, p. 49 - 53 
esenciales establecidos en la Constitución, fronteras de garantía dadas en función de valores que el constituyente juzgó supremos e inquebrantables - tales como la dignidad del individuo y los atributos que de ella derivan -, dicha prueba resultará procesalmente inadmisible y, por consiguiente, deberá ser apartada o excluida como elemento de juicio, lo antes dicho refleja la noción de la llamada máxima o regla de exclusión ${ }^{14}$.

Miranda Estrampes ${ }^{15}$, en una de sus obras más recientes continúa defendiendo la utilización del término prueba ilícita, no solo por ser el de mayor aceptación en la actualidad, sino, principalmente, por ser, en su opinión, el que mejor sirve para delimitar su concepto, sin perjuicio, de distinguir diferentes clases o modalidades atendiendo a la causa o causas que motivan su ilicitud - criterio que compartimos -.

Por su parte entiende que existen al respecto concepciones amplias y restrictivas, en el supuesto de las primeras, la prueba ilícita es aquella que atenta contra la dignidad humana ${ }^{16}$. La importancia y trascendencia de este

${ }^{14}$ Idíbem, y es que dicha regla de exclusión tiene voces a favor y en contra provenientes de todos los sectores del pensamiento jurídico, cortes y tribunales inferiores, doctrinarios, académicos han expresado y sustentado móviles y reparos, todos ellos de encomiable interés práctico y científico. Aquellas posturas que definen al proceso por la necesidad y obligación de investigar la verdad a ultranza y de manera absoluta, han de negar cualquier posibilidad de que existan prohibiciones de prueba, y con ello admitirán la eficacia del medio obtenido ilegalmente. No habrá tema que no pueda ser investigado, ni método de averiguación que no deba ser utilizado. Por el contrario, quienes hagan pie en una concepción menos absolutista, habrán de reconocer que junto al interés social en la averiguación de la verdad coexisten otras incumbencias y compromisos. Motivaciones y responsabilidades en ocasiones de superior valor y jerarquía que llevarán a impedir - o al menos restringir - una búsqueda frenética a través de métodos siempre ilimitados. El razonamiento para apoyar la regla de exclusión va por el llamado discurso ético, con recursos de orden axiológico, partiendo de la premisa de que el Estado y por ende la administración de justicia en tanto que función estatal, le es exigible un comportamiento adecuado a determinados principios éticos, en otras palabras, que en el proceso penal subyace un imperativo moral que restringe la actuación del órgano jurisdiccional a la hora de investigar y reprimir delitos. No se pretende significar que el Estado no pueda cumplir sus fines de Justicia y Seguridad, sino que esos objetivos no justifican el empleo de cualquier medio. ${ }^{15}$ Miranda Estrampes, Manuel: Concepto de prueba ilícita y su tratamiento en el proceso penal. EspecialreferenciaalaExclusionaryRuleEstadounidense.EditorialUBIJUS.México,2013,p.61 ${ }^{16}$ Silva Melero, Valentín, La prueba procesal. Tomo I. Editorial Revista de Derecho Privado, Madrid, 1963, p. 69 
última está fuera de discusión, ya que la dignidad de la persona se constituye en pieza clave del concepto de prueba ilícita: todo medio de prueba que atente contra la misma deviene ilícito, y por consiguiente inadmisible.

También hay otro grupo de autores que, partiendo de un concepto de ilicitud único para el orden jurídico en general, que identifican con la idea de violación de la norma o contrario a derecho, definen la prueba ilícita como aquella contraria a una norma de derecho, esto es, obtenida o practicada con infracción de normas del ordenamiento jurídico. El origen de la ilicitud de la prueba reside, en que fue obtenida con violación de normas jurídicas, con independencia de la categoría o naturaleza de éstas últimas (constitucionales o legales procesales o no) o incluso de disposiciones o principios generales ${ }^{17}$. Por otro lado, no siempre el concepto de ilicitud en el ámbito probatorio se identifica con el de hecho punible. Para que una prueba sea calificada de ilícita no es necesario que la conducta encaminada a su obtención sea constitutiva de infracción penal. Se opta por una concepción amplia de prueba ilícita.

Dentro de este grupo de autores, se concretan algunas precisiones en torno al rango de las normas violadas, especialmente las de rango constitucional. En este sentido se encuentra DeNTI ${ }^{18}$ que define prueba ilícita como aquella que se obtiene mediante la violación de derechos tutelados por normas diversas, y en primer lugar por normas constitucionales ${ }^{19}$. Se considera prueba ilícita aquella obtenida no sólo mediante la infracción de normas constitucionales, sino también mediante la vulneración de normas con simple rango de ley.

Mientras que la doctrina italiana con Conso ${ }^{20}$ como principal exponente,

${ }^{17}$ Vid.Devis Echandía, Hernando: Teoría general de la prueba judicial. Tomo I. 5ta Edición. Víctor P. de Zabalía Editor, Buenos Aires, 1981, p. 539; SERrA Domínguez, Manuel: Comentarios al Código Civil y Compilaciones Forales. Tomo XVI, vol. 2. Editorial Revista de Derecho Privado, Madrid 1991, p. 95; ${ }^{18}$ DentI, Vittorio, "Cientificidad de la prueba, en relación principalmente con los dictámenes periciales y la libertad de apreciación del juzgador", Revista de Derecho Procesal Iberoamericana, 1972, número 23, p. 281

${ }^{19}$ Posición que también comparte: Lozano - Higuero Pinto, Manuel "Intercepciones telefónicas y grabaciones clandestinas en el proceso penal español", Revista Universitaria de Derecho Procesal, U.N.E.D, número 4, edición especial, 1990, p 457. ${ }^{20}$ Conso, G., "Natura giuridica delle norme sulla prova nel processo penale", Revista di Diritto Processuale, 1970, p. 2

\section{0}


según el cual todas las normas relativas a las pruebas penales son normas de garantía del acusado, debiéndose considerar toda su disciplina como un instrumento de defensa para el imputado, por lo que toda infracción de las normas procesales sobre obtención y práctica de prueba debe estimarse como prueba ilícita, por cuanto implica una vulneración del derecho a un proceso con todas las garantías.

Y por otro lado, las concepciones restrictivas ${ }^{21}$, en contraposición a las antes expuestas, son aquellas que circunscriben exclusivamente el concepto de prueba el concepto de prueba ilícita a la obtenida o practicada con violación de derechos fundamentales ${ }^{22}$.

\section{Criterios de clasificación sobre ilicitudes probatorias}

Son innumerables las clasificaciones de prueba ilícita que la doctrina ha venido elaborando, por un lado se encuentra ARMENTA Deu ${ }^{23}$ quien al tratar las clases de prueba ilícita, se refiere a la ilicitud puede provenir de distintas causas: ser prueba legal y expresamente prohibida, ser irregulares o resultar defectuosas, diversificándose la prohibición en virtud de su objeto (prohibición de prestar testimonio para quienes están obligados a guardar secreto); afectar a determinados métodos de investigación (torturas, coacciones o amenazas); referirse a determinados medios de prueba (testimonio entre parientes, testimonios de referencia); violentar derechos fundamentales; ser irregulares

${ }^{21}$ GonzÁlez Montes, José Luis, "La prueba obtenida ilícitamente con violación de los derechos fundamentales(elderechoconstitucionalalapruebay suslímites)", RevistadeDerecho Procesal, 1990, número 1, p. 31; AsEnCio Mellado, José María, “La prueba. Garantías constitucionales derivadas del artículo 24.2", Revista Poder Judicial Número 4, Diciembre 1986, p. 37 - 38; Tomé García, Juan Antonio, Der echo Procesal Penal, con Santos de Ol iva, Aragoneses Martínez, Hinojosa Segovia y Muerza Esparza, Editorial Centro de Estudios Ramón Areces, Madrid, 1993, p. 468; MARTínez GarcíA, Emil iano, Eficacia de la pr ueba il ícita en el proceso penal. Editorial Tirant lo Blanch, Valencia, 2003, p. 38; Arozamena Laso, "Consideraciones generales sobre la prueba ilícita”, Revista Actualidad Penal, Número 4, enero 1999, p. 83. ${ }^{22}$ Posición que comparten: De Diego Diez, op. cit. p. 8, Ferrer Beltrán, op. cit. p. 57 y Ramos RuBio, op. cit . p. 20

${ }^{23}$ Armenta Deu, Teresa., op. cit. p. 34 
o resultar defectuosas. Puede producirse en diferentes momentos (antes o durante el mismo proceso); operar en beneficio del causante de la ilicitud o de un tercero, o finalmente, consistir en actuaciones de diferentes sujetos (acusadores o acusado).

Para Sebastián Midón ${ }^{24}$ existen las pruebas ilícitas en sí mismas y pruebas ilícitas por derivación, en la primera denominación se trata del elemento que sirve para verificar un hecho y que fue practicado u obtenido directa e inmediatamente a través de un método o procedimiento ilegal; y la segunda es aquel acto en sí mismo lícito, que permite comprobar una circunstancia fáctica, pero al que se accedió por intermedio de información obtenida desde una prueba anterior e ilícitamente recogida. Así como están las pruebas ilícitas materiales y las testimoniales, en relación a las materiales sería todo aquel elemento físico o corporal que viene a ser, directa o indirectamente, recogido, ejemplo la droga encontrada en el domicilio del imputado por un allanamiento ilegítimo, la cinta magnetofónica adquirida a través de una intervención clandestina de comunicaciones telefónicas, etc. Y la prueba ilícita testimonial sería aquella que proviene directamente de las personas a través de sus dichos.

Por su parte MirAnda Estrampes ${ }^{25}$ se refiere a las clases de prueba ilícita, en primer lugar la que se forma teniendo en cuenta el momento en que se produce la ilicitud (criterio temporal o cronológico), y el segundo, a la causa que motiva dicha ilicitud (criterio causal o material). Según el momento en que se produce la ilicitud se puede distinguir entre ilicitud extraprocesal y una ilicitud intraprocesal.

A) La ilicitud extraprocesal es aquella producida fuera de la esfera o marco del proceso propiamente dicho, en el momento de la obtención de las fuentes de prueba. Afecta por tanto, a la labor de investigación de los hechos, es decir,

\footnotetext{
${ }^{24}$ Sebastián Midón, Marcelo: Pruebas ilícitas. Análisis doctrinario y jurisprudencial. Ediciones Jurídicoas Cuyo. Argentina, 2006, p. 37 y 38

${ }^{25}$ Miranda Estrampes, Manuel, op. cit. p. 74 y ss.
} 
a la búsqueda, recogida y obtención de las fuentes de prueba ${ }^{26}$. Pudiendo ser cualquiera dentro de los intervinientes en la fase investigativa el que trabaje en la obtención de las fuentes de prueba, criterio que también comparten otros autores ${ }^{27}$.

B) La ilicitud intraprocesal es aquella que afecta a un acto procesal, es decir, cuando afecta a la proposición, admisión y práctica de la prueba durante el proceso (por ejemplo, el empleo en los interrogatorios del inculpado de medios coactivos).

PASTOR BORGONÓN ${ }^{28}$ al clasificar las prohibiciones probatorias las agrupa en dos apartados fundamentales, tomando como base la distinción entre fuentes y medios de prueba: a) aquellas derivadas de restricciones relativas a la investigación de los hechos - búsqueda y obtención de las fuentes de prueba - , y b) las que resultan de restricciones relacionadas con la incorporación de las fuentes de prueba al proceso - admisión y práctica de medios de prueba - .

Por su parte CAFFERATA Nores ${ }^{29}$ distingue entre la obtención ilegal o irregular de la prueba y su incorporación irregular al proceso.

En la doctrina italiana RAMAJOLI ${ }^{30}$ defiende la aplicación de la inutilizabilidad de las pruebas adquiridas violando las prohibiciones legalmente establecidas,

${ }^{26}$ Frente a esta tipología de pruebailícita, MIRANDA ESTRAMPES refiere que hay criterios diferentes, por un lado los que limitan la inadmisibilidad o exclusión de la prueba ilícita a la obtenida por autoridades o funcionarios públicos, pero no cuando se trata de particulares, posición que no comparte, pues cree que el tratamiento debe ser el mismo con independencia de quien o quienes realicen esta labor de búsqueda y obtención de fuentes de prueba, a estos efectos carece de importancia el carácter de la persona (funcionario público o particular) que obtiene la fuente de prueba de forma ilícita dada la eficacia erga omnes de los derechos fundamentales. ${ }^{27}$ PAstor Borgoñón, Blanca: Eficacia en el proceso de las pruebas ilícitamente obtenidas. Justicia, Revista de Derecho Procesal. No. 2, de 1986. España; LóPez BARJA DE Quiroga, Jacobo: Las escuchas telefónicas y la prueba ilegalmente obtenida. Editorial Akal, 1989, España, p. 132 - 133; GonzÁlez Montes, José Luis: La prueba ilícita. Revista Persona y Derecho. No. 54 del 2006; Bernal Cuellar, Jaime: Interceptación telefónica y grabaciones clandestinas en el proceso penal. Revista Universitaria de Derecho Penal. UNED. Número 1, 2010; Vegas Torres, Jaime: Presunción de inocencia y prueba en el proceso penal. Editorial la Ley, Madrid, 1993, p. 123 y 124. ${ }^{28}$ Pastor Borgonón, Bl anca, op. cit. p 339.

${ }^{29}$ CAfFerata Nores, José I. op. cit. p. 14

${ }^{30}$ Ramajoli, Sergio: La prova nel processo penale. Editora Padova. CEDAM. 1995, p. 316 
tanto en la fase de investigación y búsqueda de las fuentes de prueba como en la fase preparatoria propiamente dicha.

La ilicitud puede producirse en dos momentos distintos: en el momento de la obtención de las fuentes de prueba y en el momento de la incorporación de dichas fuentes de prueba al proceso. Esta clasificación responde a su vez a la distinción de Carnelutti ${ }^{31}$ entre fuentes y medios de prueba.

Otro criterio de clasificación está dado por las causas de ilicitud ${ }^{32}$, para Miranda EstramPes ${ }^{33}$ teniendo en cuenta este aspecto se pueden diferenciar las pruebas expresamente prohibidas por la ley, pruebas irregulares y/o ilegales y pruebas obtenidas o practicadas con infracción de derechos fundamentales de las personas (pruebas inconstitucionales).

Serra Domínguez ${ }^{34}$ se refiere a las causas que motivan la ilicitud del medio de prueba: a) expresamente prohibidas por la ley, b) pruebas realizadas en forma distinta a la regulada por la ley, al intentar burlar durante su práctica las formalidades legalmente establecidas en garantía de las partes, y c) pruebas obtenidas o realizadas con infracción de los derechos fundamentales de las personas reconocidos en la Constitución.

Para este autor estas últimas constituyen el capítulo más importante dentro de las pruebas ilícitas, sin embargo las mismas no agotan el contenido de prueba ilícita sino que va más allá que las derivadas de la sola violación de los derechos fundamentales, y en este sentido comparto el criterio de Miranda Estrampes sobre una concepción amplia de prueba ilícita, no constreñida a aquellos supuestos de obtención o práctica de pruebas con vulneración derechos fundamentales, a la vez que reconoce que no toda ilicitud debe comportar necesariamente las mismas consecuencias en cuanto a su inutilizabilidad

${ }^{31}$ Carnelutti, Francesco: La prueba civil. Traducción de Alcalá Zamora y Castillo. Ediciones Depalma, Buenos Aires, 1982, p. 67 y ss. ${ }^{32}$ Autores que se refieren a las causas de ilicitud: Miranda Estrampes, Manuel, op. cit. p. 79 y ss; Serra Domínguez, Manuel, op. cit . p. 94; Sebastián Midón, Marcelo, op. cit. p. 40, CafFerata Nores, José I., op. cit. p. 16

${ }^{33}$ Miranda Estrampes, Manuel, op. cit. p. 80

${ }^{34}$ Serra Domínguez, Manuel, op. cit. p. 95 
procesal (la ilicitud de la diligencia de entrada y registro en lugar cerrado no comporta siempre las mismas consecuencias, esta conclusión es aplicable a cualquier diligencia de investigación, o a cualquier medio de prueba).

\section{El rango de la norma quebrantada como centro de la polémica}

Al no existir consenso en la definición de prueba ilícita ${ }^{35}$, se valora que más allá de la nota común que la concibe como la que es obtenida infringiendo el ordenamiento jurídico, las posturas se dividen por tendencias, algunas de ellas están entre los que la refieren al ordenamiento jurídico en su integridad, los que lo concretan en lo procesal y los que se ciñen al constitucional. En este marco la polémica está en el rango de la norma quebrantada para que se considere nulo el acto de prueba.

Un sector mayoritario de la doctrina en el que se ubican JAEN VALLeJo ${ }^{36}$, De Diego Díez ${ }^{37}$, Estrella Ruíz ${ }^{38}$, Gimeno Sendra ${ }^{39}$, refiere que los actos de prueba serán nulos en tanto afecten derechos y libertades fundamentales

${ }^{35}$ Otro término debatido es el de prueba prohibida, que al decir de Asencio Mellado, José María: Prueba prohibida y prueba preconstituída. Editorial Trivium, S.A. Madrid. España, 1989, p. 75: no es plenamente aceptado por la doctrina en atención a razones varias entre las que destaca la de ser tan solo un nombre gráfico que únicamente sirve para designar todo el conjunto variado de supuestos en que la prueba es inadmisible siendo, pues, en segundo lugar, y en relación con lo anterior, dicho término un concepto no unívoco en tanto que viene a indicar una multiplicidad de situaciones por otra parte variables en función de los datos antes reseñados de legislación en la que ha de operar, reconocimiento o no expreso de su existencia, escala de valores políticos, sociales, etc. ${ }^{36}$ JAÉN VALLeJo, Manuel: Tendencias actuales de la Jurisprudencia Constitucional Penal (las garantías del proceso penal). Dykinson, Madrid 2002, p. 77. La prueba ilícitamente obtenida, la razón está en la pluralidad de aspectos que concurren en los casos en los que se plantean la vulneración del derecho fundamental sustantivo, la mayoría de las veces relacionados con escuchas telefónicas y el derecho a la inviolabilidad domiciliaria, se une la lesión del derecho al proceso con todas las garantías si se llega a producir la valoración procesal de la prueba ilícita y también en ocasiones el derecho a la presunción de inocencia. Las vulneraciones de derechos fundamentales que han sido ya reconocidas bastarían por sí solas para anular el proceso e instar su repetición por inobservancia de las reglas del juicio justo. ${ }^{37}$ De Diego Díez, ob. cit., p. 7.

${ }^{38}$ Estrella Ruiz, Manuel: La prueba ilícita. Cuadernos de estudios judiciales "Rafael Alvarado Manzano". Tegucigalpa, Honduras. 2001, p. 52.

${ }^{39}$ Gimeno Sendra, Vicente: Derecho Procesal Penal, 2da edición, Colex, Madrid, p. 371 y ss. 
establecidos en la Constitución, vulnerando de per se el derecho a un proceso con garantías de forma general.

Otro sector en el que se destacan autores como Asencio Mellado ${ }^{40}$, Sentis Melendo $^{41}$, López BarJa De Quiroga ${ }^{42}$, no precisan distinción alguna sobre el rango de la norma vulnerada a la hora de los efectos que traería la validez o eficacia del acto probatorio, sino que de las mismas normas deriva el garantismo que traen consigo de forma intrínseca.

Y por otro lado existe una postura donde se restringe el espacio para la nulidad total de la prueba ya que la decisión sobre este supuesto debe darse en caso de quebrantamiento de normas jurídicas que no tiene que ser la Constitución, y que traiga consigo la violación del derecho a un proceso garantista de forma general, valorando el caso de que se trate y los intereses que existen, en tanto contienda de partes iguales - defienden esta postura PAZ RUBIo ${ }^{43}$, GonZÁLEZ Cuellar Serrano ${ }^{44}$, y Chacón Villar- .

La esencia del problema se presenta en la determinación del rango de la norma quebrantada con la actividad probatoria y sus efectos validos o nulos, y es preciso referir que con la investigación penal de un hecho delictivo, es la búsqueda de la verdad uno de los aspectos de mayor importancia, en ese camino se encuentran exigencias propias de legalidad y seguridad jurídica a la hora de determinar si los elementos de prueba analizados fueron tomados y conservados teniendo en cuenta las reglas de la cadena de custodia. De ahí que valga la pena valorar si dichos elementos de prueba se tomaron $\mathrm{u}$ obtuvieron, o durante las etapas de la misma, se transgredieron las reglas que garantizan el respecto a los derechos fundamentales de los ciudadanos.

${ }^{40}$ Mellado Asencio, José María: Prueba prohibida y prueba pre constituida. en "Poder Judicial No. 7, Madrid, p. 121. Entre otros como MirAndA EstramPes, op. cit, p. 157 y 158, Asencio Mellado, José María: La prueba. Garantías Constitucionales derivadas del artículo 24.2”, en "Poder Judicial No. 4, Madrid, P.40, y Igartua Salaverria, Juan, Valoración de la prueba, motivación y control en el proceso penal, Ed. Tirant lo Blanch, Valencia, 1995, p. 90. ${ }^{41}$ Sentis Melendo, Santiago: La Prueba, Buenos Aires, Argentina, 1979, p.248 ${ }^{42}$ López Borja De Quiroga, Jacobo: Las escuchas telefónicas y la prueba ilegítimamente obtenida. Eitorial Akal, Madrid, 1989.

${ }^{43}$ Paz Rubio, José María: op. cit., p. 233

${ }^{44}$ González Cuellar Serrano, Nicolás: Proporcionalidad y derechos fundamentales en el proceso penal. Editorial Constitución y Leyes. Colex. España, 1990. 
Resulta loable destacar que es inoperante establecer fórmulas a priori en la determinación de la prueba ilícita, y en tal aspecto coincidimos con la tercera tendencia, pues creemos que en este campo sólo procede pronunciar pautas generales que orienten el camino a seguir, tales como la necesidad de ponderar los intereses en conflicto, apreciar las circunstancias concretas de cada caso y observar que realmente se produzca con la vulneración de la formalidad procesal inequidad y desequilibrio entre las partes, que en definitiva es la finalidad esencial del derecho a un proceso con todas las garantías.

Trasciende para OTín DEL CASTILLO ${ }^{45}$ el valor procesal de la cadena de custodia en tanto la jurisprudencia mantiene posiciones ambivalentes, siendo no obstante mayoritaria la postura que considera las irregularidades en la cadena de custodia habitualmente por la carencia de acreditación documental en alguna de sus fases, como prueba irregular y no ilícita, en cuyo caso poseería aptitud suficiente para anular su eficacia probatoria; si bien con matices, puesto que en el caso de la consideración de prueba irregular debe atenderse a la naturaleza, gravedad y acumulación de irregularidades y, sobre todo, a la posible indefensión resultante.

Ahora bien, necesario es analizar como si la cadena de custodia se rompe en alguno de sus eslabones, o en las normas establecidas a tal fin, o en la obtención de las fuentes de prueba para la investigación contaminándolas, o sin respeto de los derechos fundamentales, todo ello puede conllevar a que la prueba sea declarada ilícita.

Pero para esa valoración primero debemos identificar tres aspectos esenciales, por un lado el concepto de prueba ilícita, cuando una parte de la doctrina se refiere a la misma sólo cuando se violan derechos fundamentales de las personas, por otro lado, interesante resulta la postura de ARMENTA Deu con la sub clasificación en la teoría angloamericana y la continental, que esta última en particular gira en torno al principio de legalidad, que la obtención de las fuentes de prueba siga lo normado en ley, sino se pena con la nulidad de facto,

${ }^{45}$ Otín del Castillo, José María, op. cit. p. 98 y 99 
mientras que para Miranda Estrampes 10 más acertado es una concepción amplia, no solo relativa a la violación de derechos fundamentales sino que va más allá, incluso al momento de la obtención de las fuentes de prueba y hasta que se incorporan al proceso a través de los medios de prueba.

Un segundo aspecto, es lo relativo a la clasificación de prueba ilícita, donde la mayoría de la doctrina (como representantes de ello Miranda Estrampes y Cafferata Nores) se refiere a la clasificación en torno al momento de la ilicitud, si antes o durante el proceso denominándolas extraprocesal e intrapocesal, también SEBASTIÁN Midón se refiere a pruebas ilícitas en sí mismas y por derivación, y dentro de la misma, pruebas ilícitas materiales y testimoniales, y como parte de las materiales esta todo lo relacionado con el recojo y trabajo con las fuentes de prueba.

Y un tercer elemento el rango de la norma quebrantada, donde las tendencias que se mueven al respecto, están en primer lugar cuando se viola la norma suprema que es la Constitución, en segundo lugar cuando lo que se va en contra del ordenamiento jurídico de forma general, y los que violan una norma de índole procesal, por lo que valoramos como poco atinado ir a la especificidad de la norma en sí, y al respecto no se pueden establecer recetas para aplicar, se tendrá que valorar caso a caso según sus propias particularidades, pronunciando pautas generales de orientación, ponderar los intereses en conflicto, apreciar las circunstancias concretas, más la vulneración de la formalidad procesal que conlleva a la inequidad y desequilibrio entre las partes, como esencia de ese proceso con todas las garantías.

\section{Consideraciones finales}

La cadena de custodia supone etapas que transcurren en aras de que sean válidas las fuentes de prueba obtenidas en la investigación del hecho con caracteres de delito, y precisamente de lo que sucedería en caso de violar alguno de esos actos relativos a las fases.

Resulta muy controvertido el debate sobre los efectos derivados de la ruptura de la cadena de custodia, en ese punto expresa Figueroa Navarro ${ }^{46}$ que en 
principio son las autoridades policiales y judiciales las que garantizan la preservación de la prueba, y quien afirme la ruptura de la cadena de custodia debe probarlo. No debe admitirse como premisa, de la que parten los recurrentes, de que en principio hay que presumir las actuaciones policiales como ilegítimas e irregulares, vulneradoras de derechos fundamentales, mientras no conste lo contrario. Debiendo plantearse la ruptura de la cadena de custodia acompañada de un nivel de concreción importante, como por ejemplo en materia de drogas sostener que la sustancia analizada en el peritaje valorado como prueba de cargo no es la que la policía ocupó al acusado en el momento de su detención; en otras ocasiones se interesa la nulidad de la prueba de $\mathrm{ADN}$, concretándose en la fase de recogida de los objetos de los que se extrae la muestra, alegando posible contaminación, poniéndose en entredicho la cadena de custodia, entre otros tantos casos.

Siendo así, afirma HERNÁNDEZ - Romo VALENCIA ${ }^{47}$ al referirse a la ruptura de la cadena de custodia que no siempre traerá como consecuencia, que la prueba quede excluida, siempre que se logre acreditar que la prueba no fue alterada o modificada.

Por lo que para Del Pozo Pérez ${ }^{48}$ la prueba tiene que haberse producido con las exigibles garantías procesales, debe haberse obtenido por tanto, con observancia de la normativa relativa a la obtención de fuentes de prueba, tanto en lo relativo a las normas de enjuiciamiento como a los principios, derechos y garantías constitucionales.

$\mathrm{Y}$ en este sentido es importante señalar que se distinguen tres tendencias entorno a la prueba ilícita, la relativa al derecho a un proceso con todas las garantías por lo que toda prueba que vaya en su contra es rechazada y declarada ilícita; la del efecto preventivo o disuasorio de exclusión o exclusionary rule, deviene de la doctrina del fruto del árbol envenenado, y todo lo que derive de una prueba obtenida con vulneraciones de derechos y garantías se declara

${ }^{46}$ Figueroa Navarro, Carmen, op. cit. p. 5

${ }^{47}$ Hernández - Romo Valencia, Pablo, op. cit. p. 16

${ }^{48}$ Del Pozo Pérez, Marta, op. cit. p. 152 
ilícita de facto; y, la de la conexión de la anti juridicidad, en tanto la prueba obtenida violando derechos fundamentales lo que derive de la misma se considera como ilícita y excluida, pero sólo en determinadas circunstancias, las cuales partes de la conexión de anti juridicidad (conexión de causalidad en lo antijurídico entre la lesión ocasionada y las pruebas obtenidas). Por lo que el rango de la norma quebrantada es uno de sus pilares, resultando nulas aquellas pruebas que vulneren directamente los derechos fundamentales, y anulables las que contravengan una norma de menor jerarquía, dígase ley especial o cualquier otra normativa, en tanto este actuar podrá ser subsanable durante el transcurso del proceso.

Para que sean admitidas las pruebas en el proceso convergen tres posturas, la de la admisibilidad o no de la prueba ilícita, y una intermedia, en el caso de admitir (admisión, validez y eficacia) de las pruebas obtenidas ilícitamente, sin tener relevancia alguna el modo de obtención de las mismas, igual van a ser admitidas; la teoría de la no admisibilidad y apreciabilidad de la prueba ilícitamente obtenida, donde se valora como importante el modo de obtención de las mismas, y una teoría intermedia donde se analiza la admisibilidad y apreciabilidad de las pruebas obtenidas de forma ilícita según la ponderación de intereses en conflicto.

\section{Bibliografía}

ALONSO Pérez, Francisco (1999): Medios de investigación en el proceso penal. Editorial Dykinson. 1era Edición, Madrid, España.

ANTÓN Barberá, Francisco y De Luis y Turégano, Juan Vicente (1991): Manual de Técnica Policial. Editorial Tirant lo Blanch, Valencia España.

ARAGON, Manuel. (2002): Constitución, democracia y control. Universidad Nacional Autónoma de México. Instituto de Investigaciones Jurídicas. Serie Doctrina Jurídica No. 88. 
ARMENTA Deu, Teresa (1991). Criminalidad de bagatela y principio de oportunidad: Alemania y España. Barcelona.

ARMENTA Deu, Teresa (2009). La prueba ilícita (un estudio comparado). Ediciones Jurídicas y Sociales, S.A. Marcial Pons. Madrid. Barcelona. Buenos Aires.

ARMENTA Deu, Teresa (2011). La prueba ilícita (un estudio comparado) Segunda edición. Ediciones Jurídicas y Sociales, S.A. Marcial Pons. Madrid. Barcelona. Buenos Aires.

ARMENTA Deu, Teresa (2007). Lecciones de Derecho Procesal Penal. Tercera edición. Editorial Marcial Pons. Madrid.

ARMENTA Deu, Teresa (2014): Estudios de Justicia Penal. Editorial Marcial Pons. Barcelona.

ASENCIO Mellado, José María (1989). Prueba prohibida y prueba preconstituída. Editorial Trivium, S.A. Madrid. España.

BANACLOCHE Palao, Julio y Zarzalejos Nieto, Jesús (2010): Aspectos fundamentales de Derecho Procesal Penal. Editorial La Ley Tamas. España.

BARROETA Scheidnagel, Santiago A. (1888). Ley de enjuiciamiento criminal para las islas de Cuba y Puerto Rico. Habana. Imprenta y papelería de J. Fernández y comp. Obispo, 17, entre Oficios y Mercaderes.

BAUMANN, Jurgen. (1986). Derecho Procesal Penal, conceptos fundamentales y principios procesales. Ediciones Depalma Buenos Aires.

BECERRA y Alfonso, Pedro (1883). El jurado, su historia y su legislación en Inglaterra, Estados Unidos, Francia e Italia. Habana. 1883.

BODES Torres, Jorge. Cuba, Judicatura y procedimiento penal. 


\section{Bibliografía}

BODES Torres, Jorge. (2001). Sistema de Justicia y procedimiento penal en Cuba. Editorial de Ciencias Sociales.

BONNIER, Eduardo. (1928) Tratado teórico y práctico de las pruebas en el derecho civil y en el derecho penal. Tomo I. Madrid. Editorial Reus S.A. 1928

BONNIER, Eduardo. (1928) Tratado teórico y práctico de las pruebas en el derecho civil y en el derecho penal. Tomo II. Madrid. Editorial Reus S.A.

BORREGO, Carmelo (1999): Nuevo proceso penal. Actos y nulidades procesales. Editorial Livrosca. Caracas, Venezuela.

BRAVO, Emilio. (1864) De la administración de justicia. Madrid. Establecimiento tipográfico de Estrada, Díaz y López.

BRITO Febles, Osvaldo (1999) Manual de Criminalística. Santa Clara, Villa Clara, Cuba.

BOCANEGRA Sierra, Raúl (2005) "La teoría del acto administrativo"; Iustel, Biblioteca Jurídica Básica, I Edición.

BONECASA, Cesar, Marqués de Beccaria. Tratado de los delitos y de las penas. Editorial Atalaya, Arengreen 975. Buenos Aires.

CAFFERATA Nores, Jose Ignacio (1986): La prueba en el proceso penal. Editorial Depalma. Buenos Aires.

CAFFERATA Nores, Jose Ignacio (2000): Proceso Penal y derechos humanos. 2da Edición actualizada. Editorial Cels. Buenos Aires.

CAÑIZARES, Fernando. Teoría del Estado y del Derecho. Teoría del Estado.

CARNELUTTI, Francesco (1950). Lecciones sobre el proceso penal. Tomo I. Ediciones Jurídicas Europa América. Bosch y Cía. Editores. Chile 2970. Buenos Aires. 
CARNELUTTI, Francesco (1950). Lecciones sobre el proceso penal. Ediciones Jurídicas Europa - América. Bosch y Cía. Editores. Chile 2970. Buenos Aires. Tomo II CARNELUTTI, Francesco (1950). Cuestiones sobre el proceso penal. Traducción del volumen questioni sul proceso penale, publicado por la editorial Dott. Cesare Zuffi, Bologna.

CARNELUTTI, Francesco (1952). Estudios de Derecho Procesal. Tomo I. Ediciones Jurídicas Europa - América. Buenos Aires.

CARNELUTTI, Francesco (1952). Estudios de Derecho Procesal. Tomo II. Ediciones Jurídicas Europa - América. Buenos Aires.

CARNELUTTI, Francesco (1952). Estudios de Derecho Procesal. Tomo III. Ediciones Jurídicas Europa - América. Buenos Aires.

CASTRO, Máximo (1937). Curso de procedimientos penales. Biblioteca Jurídica Superí, Argentina.

CLARIÁ Olmedo, Jorge A., Derecho Procesal Penal. Tomo I. Rubinzal Culzoni Editores. Buenos Aires Argentina.

CLARIA Olmedo, Jorge A. (1964): Tratado de Derecho Procesal, Tomo IV, Editorial Buenos Aires.

CLEMENTE Díaz, Tirso (1984): Derecho Civil. Parte General; Tomo II, Segunda Parte, ENPES, La Habana.

CLIMENT Durán, Carlos (2005): La prueba penal. 2da Edición. Tomo I. Tirant lo Blanch. Valencia.

CLIMENT Durán, Carlos (2005): La prueba penal. 2da Edición. Tomo II. Tirant lo Blanch. Valencia.

COBO DEL ROSAL, Manuel, Quintanar Díez, Manuel y Zabala López-Gómez, Carlos (2006): Derecho Procesal Penal Español. CESEJ Ediciones. Madrid, España. 
COLOMBO, Carlos J. (1942) La negligencia en la producción de las pruebas. Valerio Abeledo Editor, Buenos Aires.

Colectivo de autores. (2002) Temas para el estudio del Derecho Procesal Penal. Primera Parte. Editorial Félix Varela La Habana.

DIAZ Mendoza, Juan (2002): Principios del proceso penal, en Colectivo de autores. Temas para el estudio del Derecho procesal penal. Primera parte. Editorial Félix Varela, La Habana

Colectivo de autores (2000): Manuales de formación continuada número 12. La prueba en el proceso penal. Consejo General del Poder Judicial, Madrid.

CONSO, Grevi (1990): Prolegomeni a un comentario breve al nuovo códice di procedura penale. Editorial CEDAM.

CHIOVENDA, José; Principios de Derecho Procesal Civil, trad. De José Casáis y Santaló de la 3ra. Edición italiana, Madrid, Edit. Reus, tomo II; 1941

DE ANTÓN y Barberá, Fracisco, De Luis y Turégano, Juan Vicente (2004): Policía Científica. Volumen I. 4ta Edición. Editorial Tirant lo Blanch. Valencia. España.

DE ANTÓN y Barberá, Fracisco, De Luis y Turégano, Juan Vicente (2004): Policía Científica. Volumen II. 4ta Edición. Editorial Tirant lo Blanch. Valencia. España.

DELLEPIANE, Antonio. (1919) Derecho Procesal. Nueva teoría general de la prueba. Buenos Aires.

DEL POZO Pérez, Marta (2014): Diligencias de investigación y cadena de custodia. Editorial Jurídica Sepin. Madrid, España.

DE MAS y Otzet, Francisco (1912). El juicio oral y la audiencia de lo criminal de Santiago de Cuba. Santiago de Cuba. 
DE NEYRA Kappler, Susana Alvarez (2008). La prueba de ADN en el proceso penal. Editorial Comares, S.L. Granada, España.

DE URBANO Castrillo, Eduardo y Torres Morato, Miguel Ángel (2012). La prueba ilícita penal. Thomson Reuters. Aranzadi. España.

ELLERO, Pietro. (1944) De la certidumbre en los juicios criminales o tratado de la prueba en materia penal. Cuarta Edición española. Madrid, Instituto editorial Reus.

ELLERO, Pedro (1913) De la certidumbre en los juicios criminales. Madrid. Volumen XVI. Hijos de Reus editores.

ESCUSOL Barra, Eladio (1993): Manual de Derecho Procesal Penal. Editorial Colex. Madrid, España.

FENECH, Miguel (1960) Derecho Procesal Penal, Editorial Labor, S.A., Volumen Primero, Tercera Edición, Barcelona Madrid.

FENECH, Miguel (1982) El proceso penal. 4ta Edición. Editorial Agesa, Madrid.

FERNÁNDEZ Entralgo, Jesús (1986) "Presunción de Inocencia, libre apreciación de la prueba y motivación de las sentencias", R.G.D., Vol. 5.

FERNÁNDEZ Entralgo, Jesús; "La motivación de las resoluciones judiciales en la doctrina del Tribunal Constitucional”, Poder Judicial, No. Especial XI, 1989.

FERNÁNDEZ Entralgo, Jesús; "Las Reglas del Juego. prohibido hacer Trampas: La Prueba ilegítimamente obtenida", en Cuadernos de Derecho Judicial, La Prueba en el Proceso Penal II, Consejo General del Poder Judicial, Madrid, 1996.

FERNÁNDEZ Pereira, Julio (1991). Teoría general, técnica, táctica y metodología criminalísticas. Primera parte. Universidad de la Habana, Facultad de Derecho. La Habana. 


\section{Bibliografía}

FERNÁNDEZ Pereira, Julio (1991). Teoría general, técnica, táctica y metodología criminalísticas. Segunda parte. Universidad de la Habana, Facultad de Derecho. La Habana.

FERNÁNDEZ Sánchez, Jesús I. (2009). Investigación criminal. Editorial Bosch. Barcelona.

FERNÁNDEZ Villazala, Tomás, García Borrego, José Antonio (2010). Derecho Procesal Penal para la policía judicial. Dykinson, S. L. Madrid.

FERRER Beltrán, Jordi, Gascón Abellán Marina, González Lagier Daniel, Taruffo Michelle (2006): Estudios sobre la prueba. Universidad Nacional Autónoma de México. México, Instituto de Investigaciones Jurídicas.

FERRAJOLI, Luigi; Derecho y Razón. Teoría del garantismo penal; Editorial Trotta, Madrid, 1997, Segunda Edición.

FERRI, Enrico (1887). Los nuevos horizontes del Derecho y del procedimiento penal. Madrid. Centro Editorial de Góngora.

FERRI, Enrico; Sociología Criminal, traducción de Antonio Soto Hernández, Ed. Góngora, Madrid, s.f.

FIERRO Méndez, Heliodoro (2012): Introducción a la Criminalística. Editorial Leyer. Bogotá, Colombia.

FIGUEROA Navarro, Carmen (2015): La cadena de custodia en el proceso penal. EDISOFER s.l. Madrid, España.

FIORINI, Bartolomé, A. (1976): Derecho Administrativo; Tomo I. Buenos Aires, Abeledo Perrot.

FOUCAULT, Michel (1976) Vigilar y Castigar. Nacimiento de la prisión. Siglo veintiuno Editores Argentina.

FLORIÁN, Eugenio (1998) De las Pruebas Penales, De la Prueba en General. Tomo I, tercera reimpresión de la 
tercera edición, editorial Temis S.A., Santa Fe de Bogotá, Colombia.

FRAMARINO Dei Malatesta, Nicola (1995): Lógica de las Pruebas en Materia Criminal, Edit. Temis, Colombia, Bogotá, (Traducción de Jorge Guerrero).

FRAMARINO, Nicolás (1997): Lógica de las pruebas en materia criminal. Tomo segundo. Madrid.

FREDAS, Pietro (1990): Introducción a la Tercera Edición de las Pruebas Penales de Florián, reimpresión de tercera edición", Edit. Temis, Bogotá, Colombia, (Traducción Castellana Jorge Guerrero).

FENECH, Miguel (1960): Derecho Procesal Penal, Ed labor, S.A, Volumen Primero, Tercera Edición, Barcelona Madrid.

FURNO, Carlo (1954). Teoría de la prueba legal. Editorial Revista de Derecho Privado. Madrid.

GARCÍA Ramírez, Sergio (2001): Algunas cuestiones del proceso penal. Editorial Reus.

GARCÍA Valdecasas, G. (1983): Parte General del Derecho Civil Español, Madrid, España.

GARCÍA Valdés, Rafael (1944). Derecho Procesal Criminal. Segunda Edición. Instituto Editorial Reus, Madrid.

GIMENO Sendra, Vicente (2004): Derecho Procesal Penal. 1era Edición, Editorial Colex. Madrid, España.

GIMENO Sendra, Vicente, Moreno Catena, Víctor, Cortés Domínguez, Valentín (2001): Lecciones de Derecho Procesal Penal. Editorial Colex. Madrid.

GÓMEZ De Liaño González, Fernando (1997). El proceso penal. Editorial FORUM. Oviedo, España.

GÓMEZ Colomer, Juan Luis (1997): El proceso penal español. 2da Edición. Editorial Tirant lo Blanch. Valencia, España. 


\section{Bibliografía}

GÓMEZ Colomer, Juan Luis (2014): La prueba de ADN en el proceso penal. Editorial Tirant lo Blanch. Valencia, España.

GIURIATI, Domingo (1812). Los errores judiciales. Editorial Lex. Madrid, España.

GOLDSCHMIDT, James. (1935). Problemas jurídicos y políticos del proceso penal. Bosch, Casa Editorial. Barcelona.

GOLDSCHMIDT, James. (1936) Teoría general de proceso. Editorial Labor S.A. Barcelona.

GÓMEZ Colomer, Juan Luis (1985), El Proceso Penal Alemán. Introducción y Normas Básicas, Barcelona, Bosch.

GÓMEZ Colomer, Juan Luis (coordinador) y del equipo de investigación, Israel, Jerold H., Kamisar, Yale., LaFave, Wayne R., King, Nancy J. (2012). Proceso Penal y Constitución de los Estados Unidos de Norteamérica. Tirant lo Blanch, Valencia, España.

GÓMEZ Orbaneja, Emilio (1976): Derecho Procesal Civil, Madrid, España.

GÓMEZ Orbaneja, Emilio Y Herce Quemada, Vicente (1954): Derecho Procesal, Vol. II, Cuarta edición, Madrid.

GONZÁLEZ Bustamante, Juan José (1941). Principios de Derecho Procesal Penal Mexicano. JUS, Revista de Derecho y ciencias sociales. México D.F.

MIRANDA Estrampes, Manuel (2013). Concepto de prueba ilícita y su tratamiento en el proceso penal. Especial referencia a la Exclusionary Rule Estadounidense. Editorial UBIJUS.

MIRANDA Estrampes, Manuel. (1997). La mínima actividad probatoria en el proceso penal. Editorial JMB. España. 
MITTERMAIER, C. J. A. (1906) Tratado de la prueba en materia criminal. sexta edición Madrid. Hijos de Reus editores.

MITTERMAIER, C. J. A. (1877) Tratado de la prueba en materia criminal. Tercera edición Madrid. Imprenta de la Revista de legislación.

MONTERO Aroca, Juan (1996): La prueba en el proceso civil. Editorial Civitas. Madrid, España.

MONTERO Aroca, Juan (2005); Manuales de Derecho Jurisdiccional I, Parte General; 14 Edición, Editorial Tirant Lo Blanch, Valencia. 


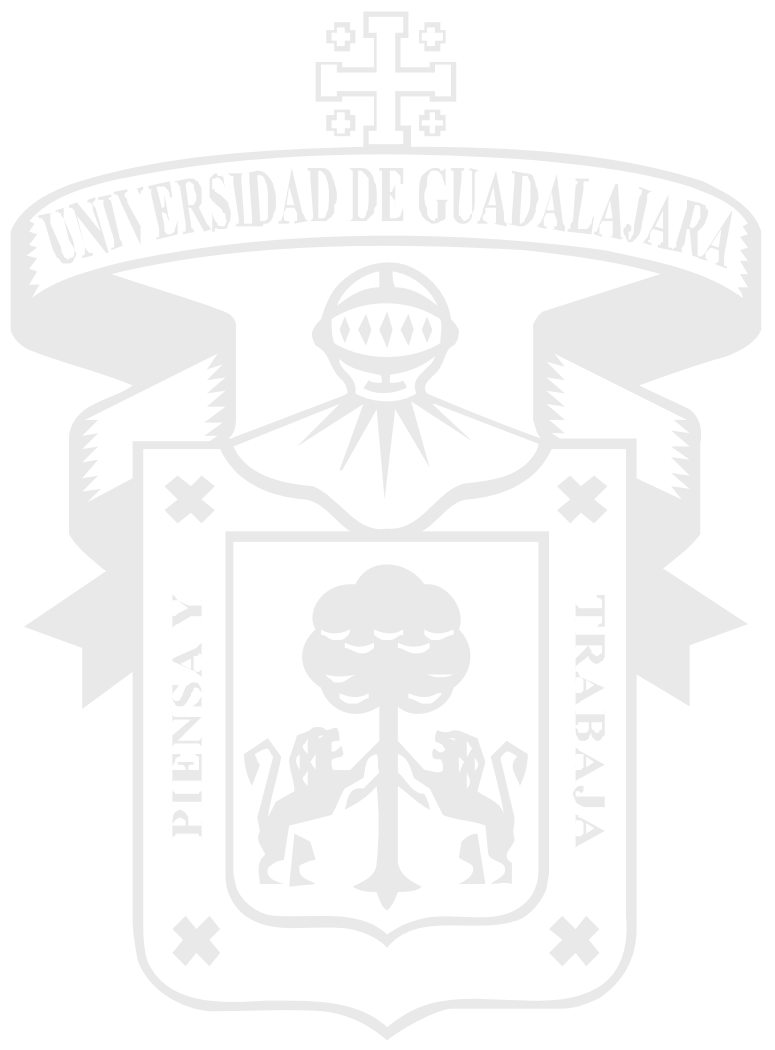

